Original Research Paper

\title{
A Meat-Derived Lactic Acid Bacteria, Lactobacillus plantarum IIA, Expresses a Functional Parvulin-Like Protein with Unique Structural Property
}

\author{
${ }^{1,2,3}$ Cahyo Budiman, ${ }^{1}$ Irma Isnafia Arief, ${ }^{3}$ Fernandes Opook and ${ }^{1}$ Muhammad Yusuf \\ ${ }^{1}$ Department of Animal Production and Technology, Faculty of Animal Science, \\ IPB University, Jl Kampus IPB Darmaga, Bogor, 16680, Indonesia \\ ${ }^{2}$ Enzyme Technology Center (ETC), Singapore Science Park, Singapore 117610 \\ ${ }^{3}$ Biotechnology Research Institute, Universiti Malaysia Sabah, Jl UMS 88400, Kota Kinabalu, Sabah Malaysia
}

Article history

Received: 13-11-2020

Revised: 24-02-2021

Accepted: 25-02-2021

Corresponding Author:

Cahyo Budiman

Department of Animal

Production and Technology,

Faculty of Animal Science, IPB

University, J1 Kampus IPB

Darmaga, Bogor, 16680.

Indonesia

Email: cahyo82@gmail.com
Abstract: The genome sequence of a Lactic Acid Bacterium (LAB) Lactobacillus plantarum IIA contains a single gene encoding a parvulin-like protein (Par-LpIIA). This protein belongs to Peptidyl Prolyl cis-trans Isomerase (PPIase) family proteins that catalyze a slow cis-trans isomerization of cis prolyl bond during protein folding. This study aims to provide molecular and biochemical evidences of the existence of Par-LpIIA in L. plantarum IIA and have an insight into its structural properties. The result showed that the gene encoding Par-LpIIA was successfully amplified using specific primers yielding a $\sim 900 \mathrm{bp}$ amplicon indicating that the gene indeed exists in its genomic DNA. BLAST analysis confirmed that the protein is a rotamase of parvulin-like protein. Further biochemical analysis demonstrated that cell lysate of $L$. plantarum IIA-1A5 exhibited remarkable PPIase activity towards peptide substrate and ability to accelerate the refolding of RNase T1, with the catalytic efficiency $\left(k_{\text {cat }} / \mathrm{K}_{\mathrm{M}}\right)$ of 1.9 and $0.02 \mu \mathrm{M}^{-1} \mathrm{~s}^{-1}$, respectively. A specific inhibitor clearly inhibited the PPIase activity for parvulin-like protein with $\mathrm{IC}_{50}$ of $230 \mathrm{nM}$ confirming that the protein encoded by Par-LpIIA gene is a parvulin-like protein and expressed in an active form. Further, the three-dimensional model of Par-LpIIA showed that this protein consists of two domains of a homolog WW domain and PPIase domain with a unique active site configuration compared to human Pin1. Altogether, we then proposed the possible roles of this protein for L. plantarum IIA.

Keywords: Peptidyl Prolyl cis-trans Isomerase, Lactobacillus plantarum, Parvulin, Active Site, Structural Homology Modelling

\section{Introduction}

Peptidyl Prolyl cis-trans Isomerase (PPIase) is a group of an enzyme catalyzing a slow cis-trans isomerization of the Xaa-Pro peptide bonds during protein folding (Lu et al., 1996; Lang et al., 1987; Stifani, 2018; Rostam et al., 2015; López-Martínez et al., 2016). This isomerization is intrinsically slow and regarded as a rate-limiting step of a folding reaction due to the high energy barrier caused by the partial double-bond character of the peptide bond (Bhagavan and Ha, 2015; Fischer and Aumüller, 2003; Chen et al., 2012). The involvement of PPIase in protein folding leads to consider this protein as a foldase (folding catalyst). Besides, some PPIase were also known to exhibit chaperone due to the ability to prevent protein aggregation and bind to a folding intermediate protein (Budiman et al., 2011).

Parvulin is the third family of PPIase, besides FK506Binding Proteins (FKBPs), cyclophilin (Chen et al., 2018; Matena et al., 2018). In contrast to FKBPs and Cyp, Par has no affinity to the immunosuppressant, FK506 or CsA (Matena et al., 2018; Tuccinardi and Tizzolio, 2019; Barik, 2006; Romano et al., 2004; Maruyama et al., 2004). Besides, while FKBPs and Cyp prefer unphosphorylated Xaa residue preceding proline, parvulin specifically catalyzes phosphorylated prolyl bond 
(phospho-Ser-Pro or phospho-Thr-Pro (Matena et al., 2018; Rostam et al., 2015). A prominent parvulin is the mitotic regulator Pin1 (Chen et al., 2018; Rostam et al., 2015) involved in cell cycle regulation, protein folding disorders such as Alzheimer's or Parkinson's disease (Mueller and Bayer, 2008; Nakatsu et al., 2011) and cancer (Lee and Liou, 2018).

Parvulin was found in prokaryote or eukaryote (Rostam et al., 2015; Nakatsu et al., 2011) and structurally consist of PPIase domain, responsible for catalysis and additional domain(s) which thought to be important for binding to protein substrates/partners (Maruyama et al., 2004). While the PPIase domain is structurally conserved among Par family members, the additional domain was found to be more variable. Generally, prokaryotic parvulins have a chaperon-like activity and eukaryotic parvulins have been linked to several aspects of gene regulation and cell cycle progression. The PPIase domain of parvulin is characterized by the presence of conserved amino acids like histidine, isoleucine and leucine (Fanghänel and Fischer, 2004; Lu, 2003; Rippmann et al., 2000; Shaw, 2002).

Lactobacillus plantarum IIA is a Gram-positive of Lactic Acid Bacteria (LAB) isolated from beef that displays some probiotic characteristics (Arief et al., 2015). Like other LAB, L. plantarum IIA is promising for some applications including as a starter for food fermentation or host cells for the production of bioactive compounds. The genome sequence of this bacterium (will be published somewhere else) revealed a single gene encoding a member of the third family of PPIase, parvulin, and designated as Par-LpIIA. The presence of a PPIase member in L. plantarum IIA is interesting since it might imply the essential role of this PPIase in the cellular event of Par-LpIIA. Besides, to our knowledge, only a few parvulin members were so far reported with no structural report on this protein. To note, the study on the functionality of PPIase from LAB are limited. Some reports indicated the presence of genes encoding cyclophilin-like and FKBP-like proteins in L. helveticus and L. lactis, respectively (Broadbent et al., 2011; Trémillon et al., 2012; Bolotin et al., 2001). Further, the prsA-like gene of L. lactis was also reported to encode a protein with PPIase motif and possibly be involved in the protein maturation and secretion of this bacterium (Drouault et al., 2002). Nevertheless, no report so far for the parvulin-like protein in LAB. In this study, we confirmed the evidence of Par-LpIIA existence through molecular and biochemical approaches. The three-dimensional model of Par-LpIIA was also built under structural homology modeling which provides an insight into structural features related to a catalytic property of this protein. To note, this is the first structural report of parvulin-like protein from LAB family.

\section{Methods}

\section{Gene Amplification}

Genomic DNA of L. plantarum IIA was extracted using DNA QIAamp genomic DNA kits (Qiagen, USA) according to manufacturer protocol. The genomic DNA was then used as a template for gene amplification. Amplification was performed using Polymerase Chain Reaction (PCR) with KOD FX Neo PCR kit (Toyobo, Japan) according to the manufacturer's protocol with slight modifications. The primers used for the amplification were 5ATGAAGAAAAAAATGCGCCTTAAAGTATTATTG G-3 (forward) and 5TTAATTCGTTGTCGCAAGCTTCTTATAACTATC-3 (reverse). PCR product was then separated under $1 \%$ agarose gel and visualized under ethidium bromide staining. The amplicon migrated at expected sized was then excised and extracted using The QIAquick Gel Extraction Kit. The purified DNA was sequenced using the Prism 310 DNA sequencer (Applied Biosystems) using the above primers. All oligonucleotides were synthesized by 1 stBase DNA sequence service (Singapore).

\section{DNA and Amino Acid Sequence Analysis}

The DNA sequence obtained was subjected to BLAST analysis and translated to amino acid sequence using Expert Protein Analysis System (ExPASy) Translation Tool (https://web.expasy.org/translate/). The deduced amino acid sequence was then used for analysis using Protein Calculator v3.4 (http://protcalc.sourceforge.net) and used for the alignment with other parvulin members, whose the sequences were retrieved from the GeneBank. The alignment was performed using the ClustalW program at EBI (http://www.ebi.ac.uk/clustalw/) and PPIase domain sequence was identified based on the conservation region of PPIase domain of human Pin1, which was identified before (Fanghänel and Fischer, 2004).

\section{PPIase Activity}

For the assay, cell lysate of L. plantarum IIA-1A5 (CL-LpIIA) was firstly obtained from the sonication of L. plantarum IIA followed by ultracentrifugation at $35,000 \mathrm{~g}$ for $30 \mathrm{~min}$. Measurements were carried out as described by (Uchida et al., 2003) using a WFY(pS)PRpNA peptide substrate (Bachem, Heidelberg, Germany). Briefly, a $1 \mathrm{~mL}$ reaction mixture containing 0.45 mg. $\mathrm{mL}^{-1} \alpha$-chymotrypsin and the protein of CL-LpIIA in $50 \mathrm{mM}$ HEPES and $100 \mathrm{mM} \mathrm{NaCl}, \mathrm{pH}$ 8.0, was prechilled to the measurement temperature $(10,15,20$ or $25^{\circ} \mathrm{C}$ ) and then rapidly mixed into a cuvette containing the substrate WFY(pS)PR-pNA peptide substrate (Bachem, Heidelberg, Germany). The substrate was previously prepared by dissolving at concentration of $5 \mathrm{mM}$ in 470 
$\mathrm{mM} \mathrm{LiCl/trifluoroethanol} \mathrm{(Kofron} \mathrm{et} \mathrm{al.,} \mathrm{1991)} \mathrm{as} \mathrm{a} \mathrm{stock}$ concentration. The catalytic efficiency $\left(k c_{a t} / K_{\mathrm{M}}\right)$ was calculated as described previously (Janowski et al., 1997). The activity at $10^{\circ} \mathrm{C}$ was adjusted as $100 \%$. To determine the effect of $\mathrm{pH}$ on PPIase activity, the assay was also measured at $10^{\circ} \mathrm{C}$ in various buffer $\mathrm{pH}$ ranging from 2.0 to 12.0. The highest activity was adjusted as $100 \%$.

\section{Inhibition Studies}

The WFY(pS)PR-pNA peptide substrate (Bachem, Heidelberg, Germany) was used in the measurements for inhibition studies. The inhibitors used in this experiment were FK506, Cyclosporine (CsA) and juglone (Sigma Aldrich, USA). Stock solutions of the inhibitors were prepared in 50\% ethanol. The CL-LpIIA was firstly incubated with one of the inhibitor, at different concentrations, for $15 \mathrm{~min}$ at $10^{\circ} \mathrm{C}$ and then used for the PPIase activity assay as described above. The catalytic efficiency obtained from the assay without any inhibitor was adjusted to $100 \%$ activity according to Uchida et al. (2003) and Budiman et al. (2018).

\section{Substrate Specificity}

Substrate specificity was measured by measuring PPIase activity as described above using Suc-Ala-XaaPro-Phe-NH-Np as a substrate obtained from Bachem (Heidelberg, Germany). Xaa represents a variable amino acyl residue in the $\mathrm{P} 1$ position of various oligopeptide substrates used for investigation of the substrate specificity. The catalytic efficiency obtained from Suc-Ala-Leu-Pro-Phe-NH-Np was adjusted to $100 \%$ activity according to (Uchida et al., 2003; Budiman et al., 2018).

\section{Catalysis of Protein Folding}

The assay was performed according to (Budiman et al., 2009; Wojtkiewicz et al., 2020; Uchida et al., 1999). Briefly, RNase $\mathrm{T}_{1}(16 \mu \mathrm{M})$ (Funakoshi Co., Ltd., Tokyo, Japan) was first unfolded by incubating it in $20 \mathrm{mM}$ sodium phosphate ( $\mathrm{pH} 8.0$ ) containing $0.1 \mathrm{mM}$ EDTA and $6.2 \mathrm{M}$ guanidine hydrochloride at $10^{\circ} \mathrm{C}$ overnight. Refolding was then initiated by diluting this solution 80 -fold with $20 \mathrm{mM}$ sodium phosphate ( $\mathrm{pH}$ 8.0) containing $100 \mathrm{mM} \mathrm{NaCl}$ in the presence or absence of the CL-LpIIA. The final concentrations of RNase $\mathrm{T}_{1}$ was $2 \mu \mathrm{M}$. The refolding reaction was monitored by measuring the increase in tryptophan fluorescence with an F-2000 spectrofluorometer (Hitachi High-Technologies Co.). The excitation and emission wavelengths were 295 and $323 \mathrm{~nm}$, respectively and the band width was $10 \mathrm{~nm}$. The refolding curves were analyzed with double exponential fit (Ramm and Pluckthun, 2000). The $k_{\text {cat }} / K_{\mathrm{M}}$ values were calculated from the relationship mentioned above, where $k_{\mathrm{p}}$ and $k_{\mathrm{n}}$ represent the first-order rate constants for the faster refolding phase of RNase $\mathrm{T}_{1}$ in the presence and absence of the enzyme, respectively (Suzuki et al., 2004).

\section{Structural Homology Modelling}

The amino acid sequence of Par-LpIIA was subjected for comparative homology modelling via SWIS-MODEL Server (Schwede et al., 2003), 3DJIGSAW (Bates et al., 2001) and PHYRE2 server (Kelley and Sternberg, 2009). Finally, once the 3D structures were generated, model validations were performed. Backbone conformation of all models was evaluated by analysis of Psi/Phi Ramachandran plot using RAMPAGE program (Lovell et al., 2003). The overall stereochemical quality of the final developed model for each model was assessed by the program PROCHECK. G-factor was calculated for the developed model using PROCHECK. Environment profile of final developed model was checked using Verify-3D (Structure Evaluation Server).

The best model was then used for structural alignment to identify putative active site residues. Structural alignment of model structure of Par-LpIIA to human Par (PDB ID: 1 nmv) was performed in PyMol (https://pymol.org/2/). Active sites of human Par, which were identified according to (Fanghänel and Fischer, 2004), were manually aligned to corresponding residues model structure of Par-LpIIA. These corresponding residues were then considered as active sites of Par-LpIIA.

\section{Results}

\section{Gene Amplification and Analysis}

To confirm if the gene encoding Par-LpIIA really exists in the genome of $L$. plantarum IIA, Polymerase Chain Reaction (PCR) was performed using a series of primers designated based on the gene sequence. The amplicon corresponds to the apparent size of $900 \mathrm{bp}$ was successfully obtained (Fig. 1a). Further, DNA sequence of the amplicon is also exactly matched with the sequence obtained from the whole genome sequence (Fig. 1b). This suggested that the genomic DNA of $L$. plantarum IIA indeed harbour a gene encoding Par-LpIIA. This also, to some extent, validated genome assembly, followed by annotation, of this strain.

The full-length DNA sequence of Par-LpIIA encodes a polypeptide of 299 amino acids with a predicted molecular mass of $33.14 \mathrm{kDa}$ and a theoretical isoelectric point of 9.57 (Fig. 2a). This size is considerably higher to that of the average size of the PPIase domain of parvulin members. BLAST analysis of the whole amino acid sequence also displayed high similarities $(>90 \%)$ to putative PPIase from Lactobacillus casei BL23, Lactobacillus acidophilus NCFM, Lactobacillus gasseri ATCC 33323, Lactobacillus casei BL23, Pediococcus pentosaceus ATCC 25745, Lactobacillus plantarum 
WCFS1, Lactobacillus delbrueckii subsp. Bulgaricus ATCC 1842, Lactobacillus brevis ATCC 367, Lactobacillus reuteri JCM 1112, Lactobacillus fermentum IFO 3956, Listeria monocytogenes EGD-e, Bacillus anthracis str. 'Ames Ancestor', Listeria monocytogenes EGD-e, Leuconostoc mesenteroides subsp. Mesenteroides ATCC 829. BLAST also revealed that the sequence contains a so-called Rotamase- 2 superfamily domain that spans from His 150 to Lys 232 and was predicted as a PPIase domain. The other residues are predicted to be organized as a non-PPIase domain. Multiple amino acid sequence alignment of Par-LpIIA with other well-studied parvulin is shown in Fig. 2b. The amino acid sequence of Par-LpIIA showed 21.15, 22.22 and 25.58\% similarities to human Pin1, Par14 and E. coli Parvulin (Eco-Par), respectively. Meanwhile, it shows very high similarity (>99\%) to parvulin of L. casei and L. paracesi.

\section{PPIase Activity, Inhibition and Specificity}

Although it was confirmed that the gene of Par-LpIIA exists, this protein's functionality remains to be confirmed. The functionality refers to the ability of Par-LpIIA to exhibit specific catalytic activity and bind or inhibited by specific inhibitors. In this study, specific PPIase activity of Par-LpIIA in CL-LpIIA was determined using a proteasecoupling method, in which the enzyme catalyzes the slow isomerization of Ser-Pro bond of the substrate followed by the releasing of pNA moiety when the substrate was cleaved by chymotrypsin upon the rotation of Ser-Pro bond to trans configuration. The result showed that $k_{\text {cat }} / \mathrm{K}_{\mathrm{M}}$ of apparent PPIase activity of CL-LpIIA was calculated to be $9.8 \mu \mathrm{M}^{-1} \mathrm{~s}^{-1}$ (Fig. 3a). Nevertheless, it remains to be confirmed if the activity of CL-LpIIA is originated from Par-LpIIA or other types of isomerase. To confirm, the catalytic activity was also measured in the presence of a specific inhibitor for FKBP (FK506) and Cyclosporine (CsA). None of the inhibitors were able to remarkably inhibit the catalytic activity of the cell lysate (Fig. 3b). Further, when a specific inhibitor of parvulin (juglone) was used in the measurement, it showed a reduction of PPIase activity of CL-LpIIA with an $\mathrm{IC}_{50}$ value of about $200 \mathrm{nM}$ (Fig. 3b).

Further, the temperature dependency of the PPIase activity of CL-LpIIA showed that the activity increased as the reaction temperature increased from 10 to $25^{\circ} \mathrm{C}$ (Fig. 4a). The PPIase activity was not measured at temperatures higher than $30^{\circ} \mathrm{C}$, because the rate for spontaneous prolyl isomerization reaction was too high to determine those catalyzed by PPIases accurately. Further, Fig. 4b showed that the optimum $\mathrm{pH}$ of PPIase activity of CL-LpIIA was observed at pH 5.0.

The substrate specificity of CL-LpIIA was shown in Fig. 5. In this study, seven (7) variants of the tetrapeptide substrates were used by replacing Xaa to Leu or Ala or Phe or Gln or Arg or Lys or His. All these residues have differences in polarity and structural bulkiness that might affect the fitting into the binding pocket. Figure 5 showed the preference of Par-LpIIA towards Xaa at P1 position followed the order of Leu $>$ Arg $>$ Gln $>$ Ala $>$ Lys $>$ Phe $>$ His .

\section{Catalysis of Protein Folding}

Figure 6 showed the refolding course of RNase T1 in the absence or in the presence of CL-LpIIA. RNase T1 is known to have two prolyl bonds two peptidyl-prolyl bonds (Tyr38-Pro39 and Ser54-Pro55) and its refolding rate is limited by the cis-trans isomerization of these bonds (Kiefhaber et al., 1990a; 1990b). This experiment was conducted to confirm if the cell lysate of LpIIA, which is assumed to contain Par-LpIIA, is able to accelerate the slow refolding of RNase T1.

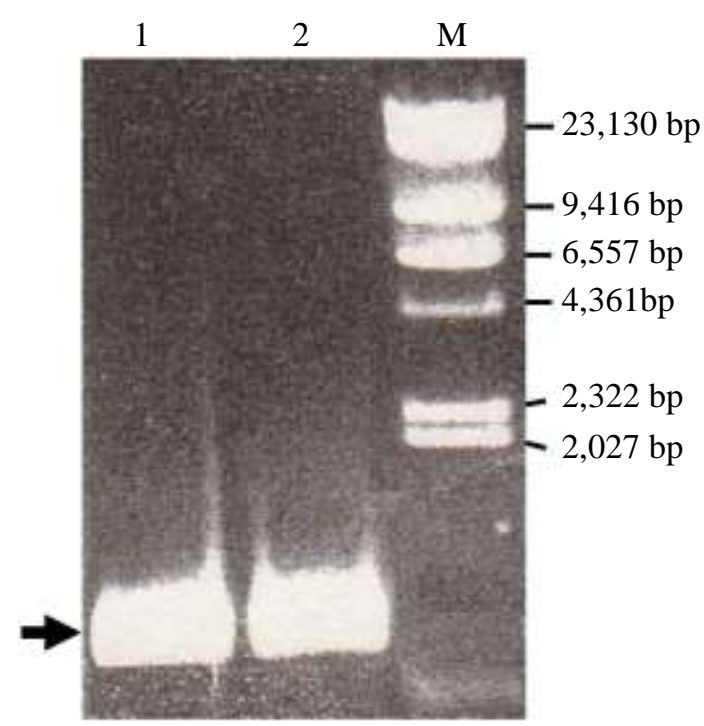

(a) 


\begin{tabular}{|c|c|}
\hline Gene-target & atgaagaaaaaatgcgccttaaagtattattggcaagtaccgcaactgctttactgctg \\
\hline Sequence-result & 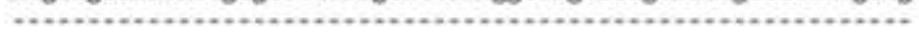 \\
\hline Gene-target & ctaagcggttgtcagtcaaatcaggccgaccaaacagttgcgacctattcaggcggcaag \\
\hline Sequence-result & 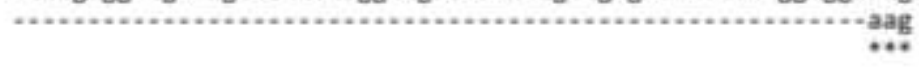 \\
\hline Gene-target & gtgactgaaagtaacttctacaaggaactcaaacagtcaccaacgacaaagaccatgctt \\
\hline Sequence-result & $\begin{array}{l}\text { gtgactgaaagtaacttctacaaggaactcaaacagtcaccaacgacaagaccatgctt } \\
\text {. }\end{array}$ \\
\hline Gene-target & gctaacatgctcatttatcgtgcattgaatcatgcctatggaaaatcggttagcactaaa \\
\hline Sequence-result & 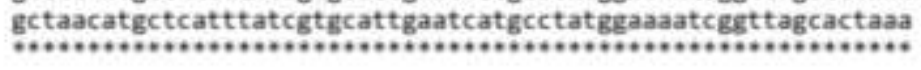 \\
\hline Gene-target & acagttaatgacgcctatgatagctacaaacaacaatacggcgaaarttcgatgctttc \\
\hline Sequence-result & $\begin{array}{l}\text { acagttaatgacgcctatgatagctacaaacaacaatacggcgaaatttcgatgctttc } \\
\ldots\end{array}$ \\
\hline Gene-target & ttaagtcaaareggttcagtcgcagtagcttcaaggaaagcctacgaaccaacttttta \\
\hline Sequence-result & $\begin{array}{l}\text { ttaagtcaaaacggtttcagtcgcagtagcttcaaggaagectacgaaccaacttttta } \\
\ldots \ldots+\ldots\end{array}$ \\
\hline Gene-target & agtgaagttgcactgaaaagttaaaaaggtttctgaaagccagctcaagaccgcttgg \\
\hline Sequence-result & $\begin{array}{l}\text { agtgaagttgcactgaaaaagttaaaaaaggtttctgaagecagctcaagaccgcttgg } \\
0.0 .\end{array}$ \\
\hline Gene-target & aagacctatcagcccaaagtgactgtccaacatattctaactagcgacgaggacactgct \\
\hline Sequence-result & 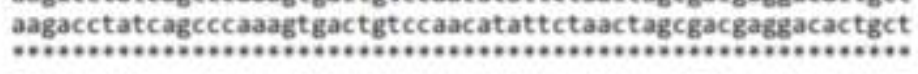 \\
\hline Gene-target & aagcaagttatcagtgatttagcagctggcaaggattttgccacgcttgcgaaaactgat \\
\hline Sequence-result & aagcaagttatcagtgatttagcagctggcaaggattttgccacgcttgcgaaactgat \\
\hline Gene-target & tccattgatactgcgactaaagataacggcgggaagattagttttgaatcaaacaataaa \\
\hline Sequence-result & $\begin{array}{l}\text { tccattgatactgcgactaaagataacggcgggaagattagttttgaatcaaacaataaa } \\
\text {. }\end{array}$ \\
\hline Gene-target & acgctcgatgccacatttaaggatgctgcctacaaattaaaaaatggtgactacacgcag \\
\hline Sequence-result & 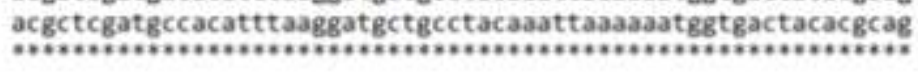 \\
\hline Gene-target & acaccagtcaagtgacagacgegtatgaagttattaaaatgattaaccatcccgccaaa \\
\hline Sequence-result & 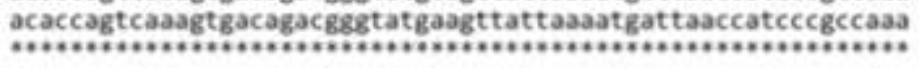 \\
\hline Gene-target & ggcacctttactagcagcaaaaaggcgctaactgccagcgtttacgctaaatggtccegc \\
\hline Sequence-result & 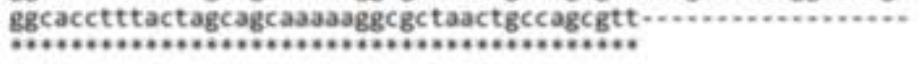 \\
\hline Gene-target & gattcaagcatcatgcaacgcgttatcagtcaggtattgaagaaccagcatgtgacgatt \\
\hline Sequence-result & (2) \\
\hline Gene-target & aaagacaaggatcttgcggatgcgctagatagttataagaagcttgcgacaacgaattaa \\
\hline Sequence-result & n. \\
\hline
\end{tabular}

Fig. 1: (a) Amplification of Par-LpIIA gene. Lane M corresponds to a $\lambda$ DNA/HindIII Markers, while Lane 1 and 2 correspond to the Polymerase Chain Reaction (PCR) products of the gene from two independent reactions, (b) Comparison between DNA sequence of Par-LpIIA obtained from the sequencing of PCR product (Sequence-result) and that of from whole-genome sequencing (Gene-target)

The ability should refer to the presence of a functional Par-LpIIA as only PPIase protein is able to catalyze the slow refolding rate due to cis-prolyl bond isomerization.
Figure 6 clearly showed that fluorescence intensity of the refolding of RNase $T_{1}$ in the presence of crude extract containing Par-LpIIA reached the maximum intensity faster 
than that of in the absence of the crude extract. This clearly suggested that CL-LpIIA was able to facilitate the catalysis of an RNase T1 refolding course. To note, Fig. 6 also indicated that the catalysis of refolding by CL-LpIIA was a concentration-dependent manner with the calculated $k_{\text {cat }} / K_{\mathrm{M}}$ value of $0.02 \mu \mathrm{M}^{-1} \mathrm{~s}^{-1}$.

\section{Three Dimensional Model of Par-LpIIA}

Structural homology modeling of Par-LpIIA is unavoidable to obtain a comprehensive understanding of the functional mechanism of this PPIase member. Structural homology modeling under various platforms used in this study yielded 4 models that have similar overall structures with RMSD about $0.51 \AA$. However, structural validation through Ramachandran Plot revealed that the model from PHYRE2 server platform is more acceptable since it has fewer residues $(<1 \%)$ in disallowed regions. Noteworthy, the secondary and model structure showed that these residues are located in the flexible regions hence caused the unique steric hindrance properties. The overall main-chain and side-chain parameters, as evaluated by PROCHECK, are all very favorable. No clash between residues of the model has also been identified in the viewer. Further validation under verify-3D also revealed that all residues are reasonably folded as indicated by zero compatibility score. Accordingly, we believed this model is acceptable for further analysis.

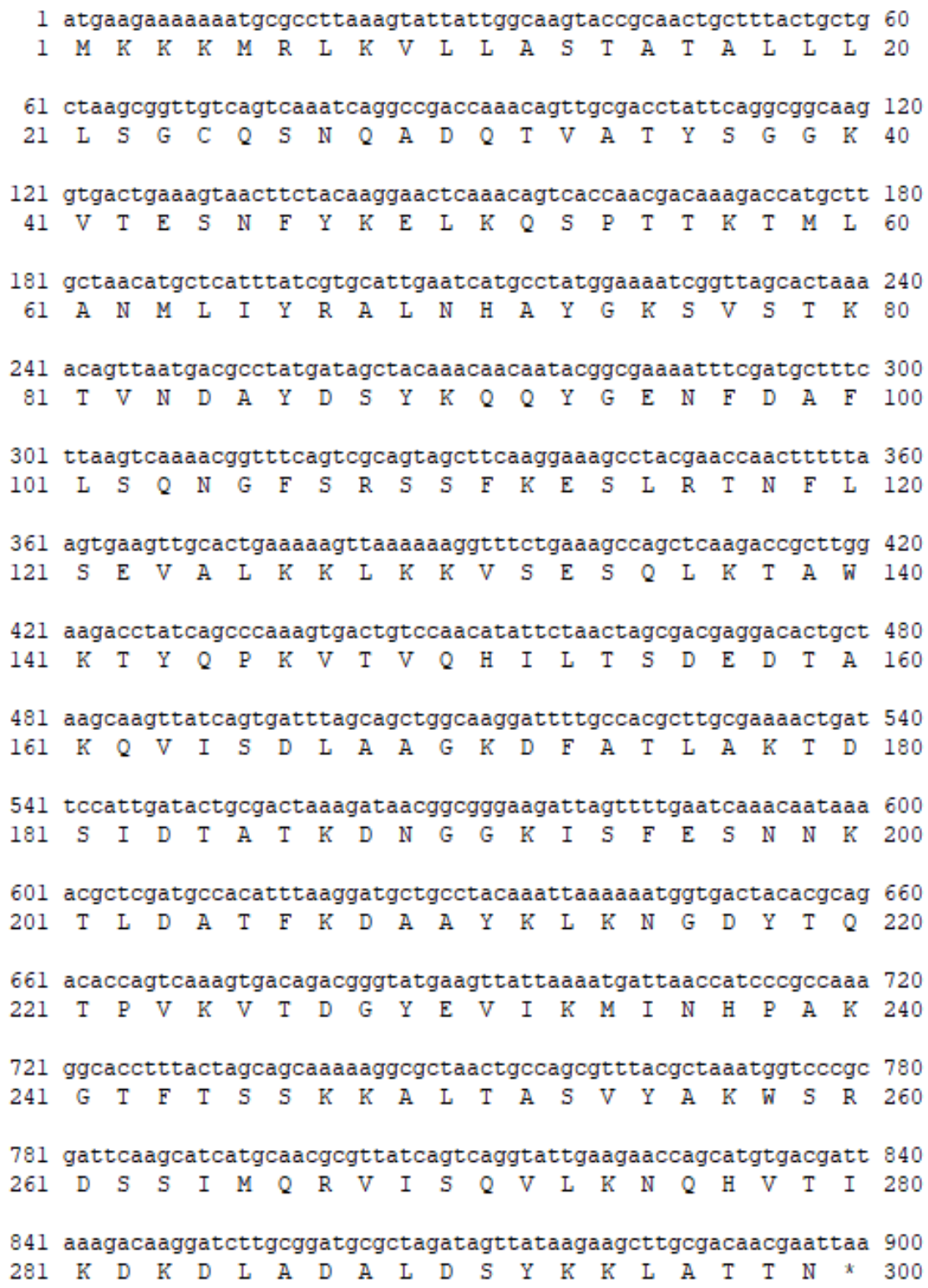




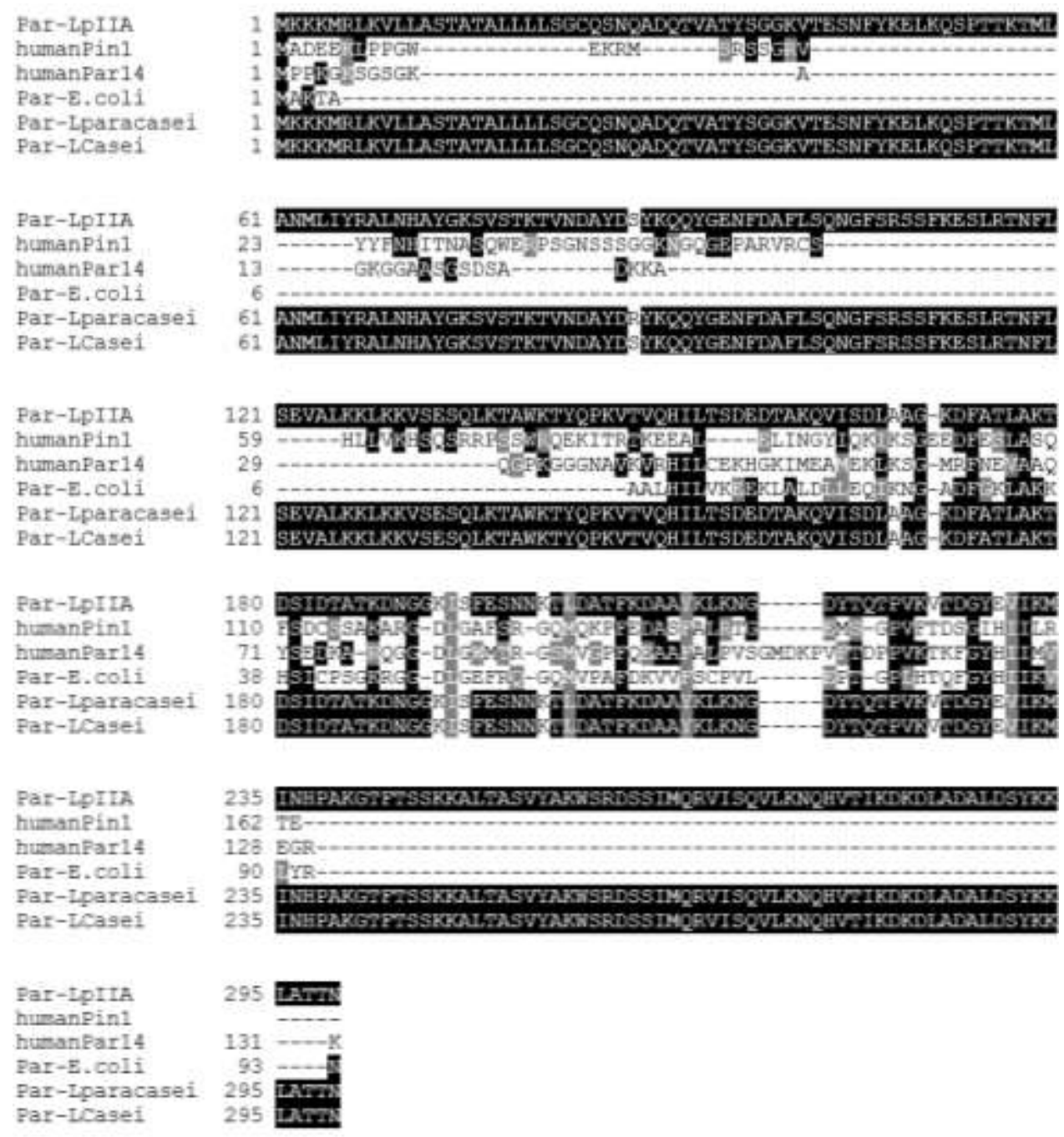

(b)

Fig. 2: (a) The amino acid sequence of Par-LpIIA translated from its DNA sequence, (b) Pairwise sequence alignment between ParLpIIA with human parvulin 1 (human Pin1), human Parvulin 14 (human Par14), E. coli Parvulin 10 (Par-E. coli), Lactobacillus paracasei Parvulin (Par-Lparacasei) and L. casei Parvulin (Par-Lcasei)
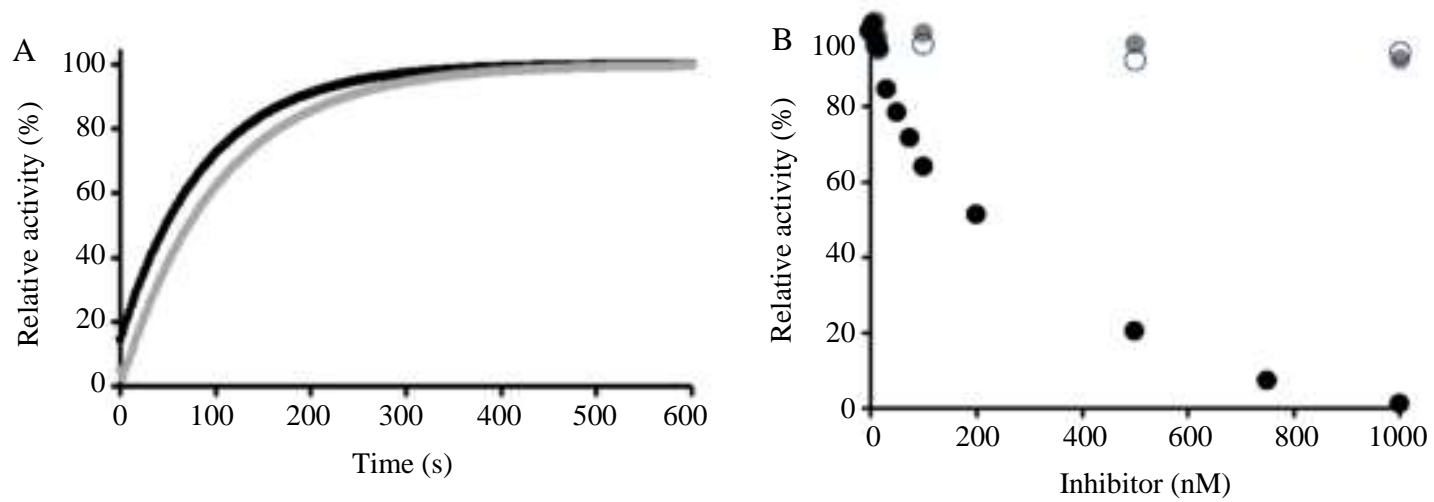

Fig. 3: (a) A representative of the time course of cis-trans prolyl bond isomerization of WFY(pS)PR-pNA peptide in the absence (grey solid line) and in the presence (black solid line) of $3.5 \mathrm{nM}$ of CL-LpIIA, (b) The inhibition of apparent PPIase catalytic activity of CL-LpIIA by FK506 (open circle), cyclosporine (gray circle) and juglone (black circle) 

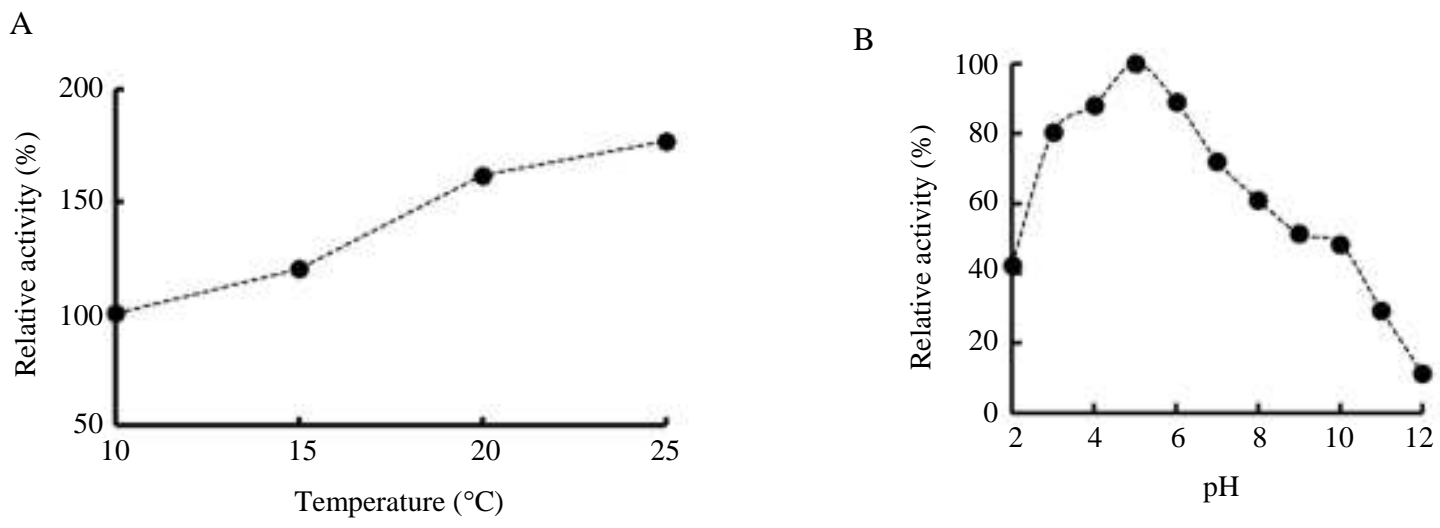

Fig. 4: (a) Temperature and, (b) pH-dependency activity of CL-LpIIA

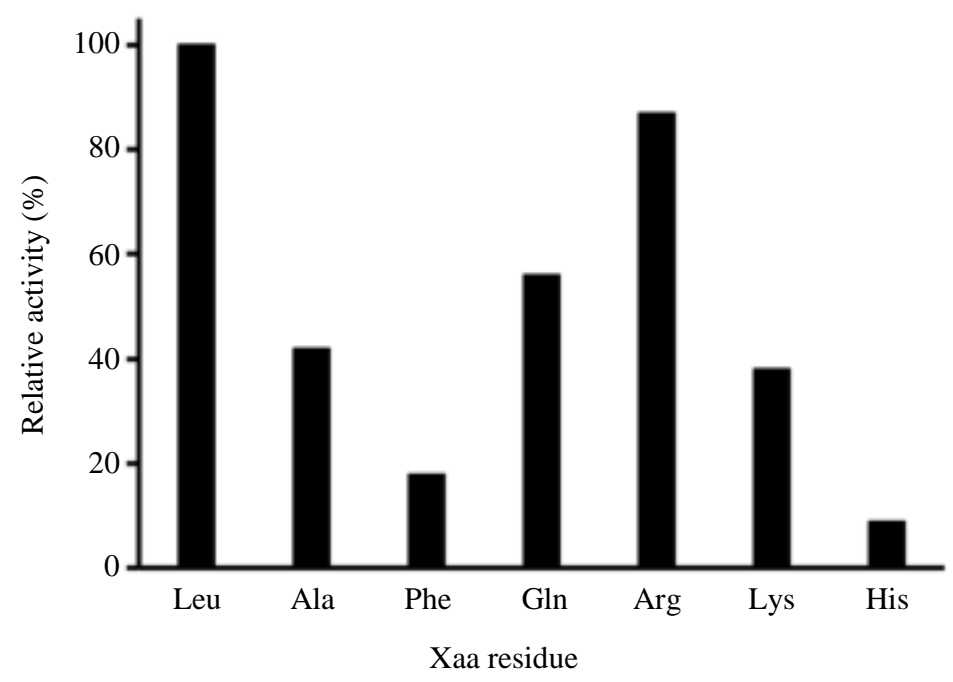

Fig. 5: PPIase catalytic activity of CL-LpIIA towards peptide substrate with the various amino acids at the Xaa position. The activity towards Suc-Ala-Leu-Pro-Phe-pNA was adjusted as $100 \%$

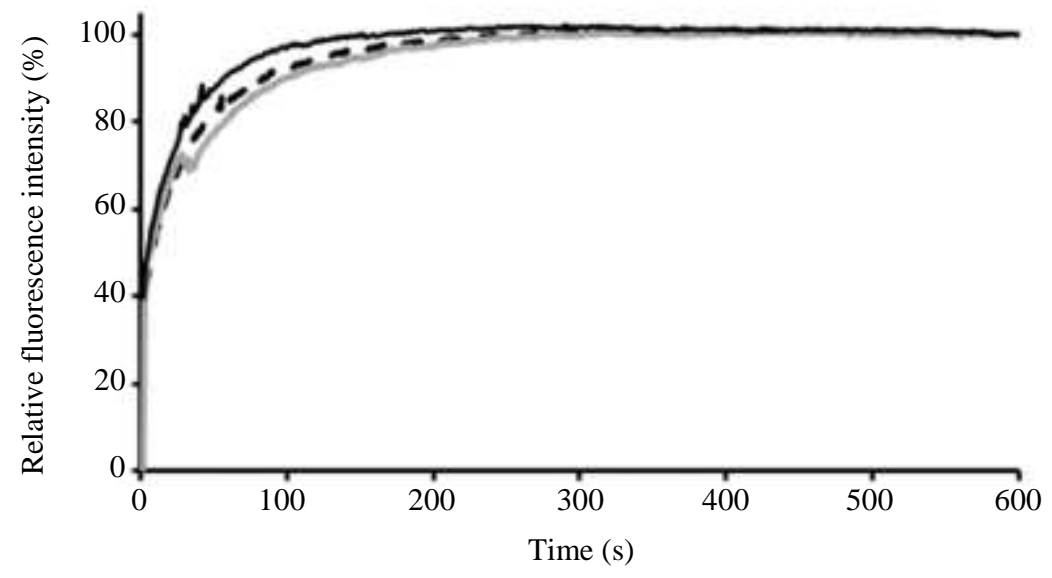

Fig. 6: Refolding course of RNase $\mathrm{T}_{1}$ in the absence (grey solid line) or in the presence of $1 \mathrm{nM}$ (black dashed line) or $10 \mathrm{nM}$ (black solid line) of CL-LpIIA 
The overall structure of Par-LpIIA indicated that this protein folded into two separated domains of the WW and PPIase domains (Fig. 7a). The WW domain is formed by the residues of Met1-Lys126 and Phe243-Asp282. These residues organized into $3 \beta$ sheets $(\beta 1, \beta 2$ and $\beta 6)$ and $6 \alpha$-helixes $(\alpha 1, \alpha 2, \alpha 3, \alpha 4$, $\alpha 9$ and $\alpha 10)$. Meanwhile, the PPIase domain is formed by the residues of Pro145-Thr242 which organized into $3 \beta$-sheets ( $\beta 3, \beta 4$ and $\beta 5$ ) and $3 \alpha$-helixes $(\alpha 6, \alpha 7$ and $\alpha 8$ ). The structural alignment with well-studied human Pin1 (PDB ID: 1NMV) showed yielded an
RMSD of $2.42 \AA$ which suggested that the two proteins were not really similar (Fig. 7b). The differences mainly found in the WW domain, whereby the homolog of WW domain of Par-LpIIA is shown to be remarkably folded into a non-globular shape and has a larger structure than that of Pin1. The difference in this domain might also explain the bigger theoretical size of Par-LpIIA than the other Par members. On the other side, PPIase domain of ParLpIIA was shown to be similar to that of Pin1 with an RMSD of $0.81 \AA$ (Fig. 7c).

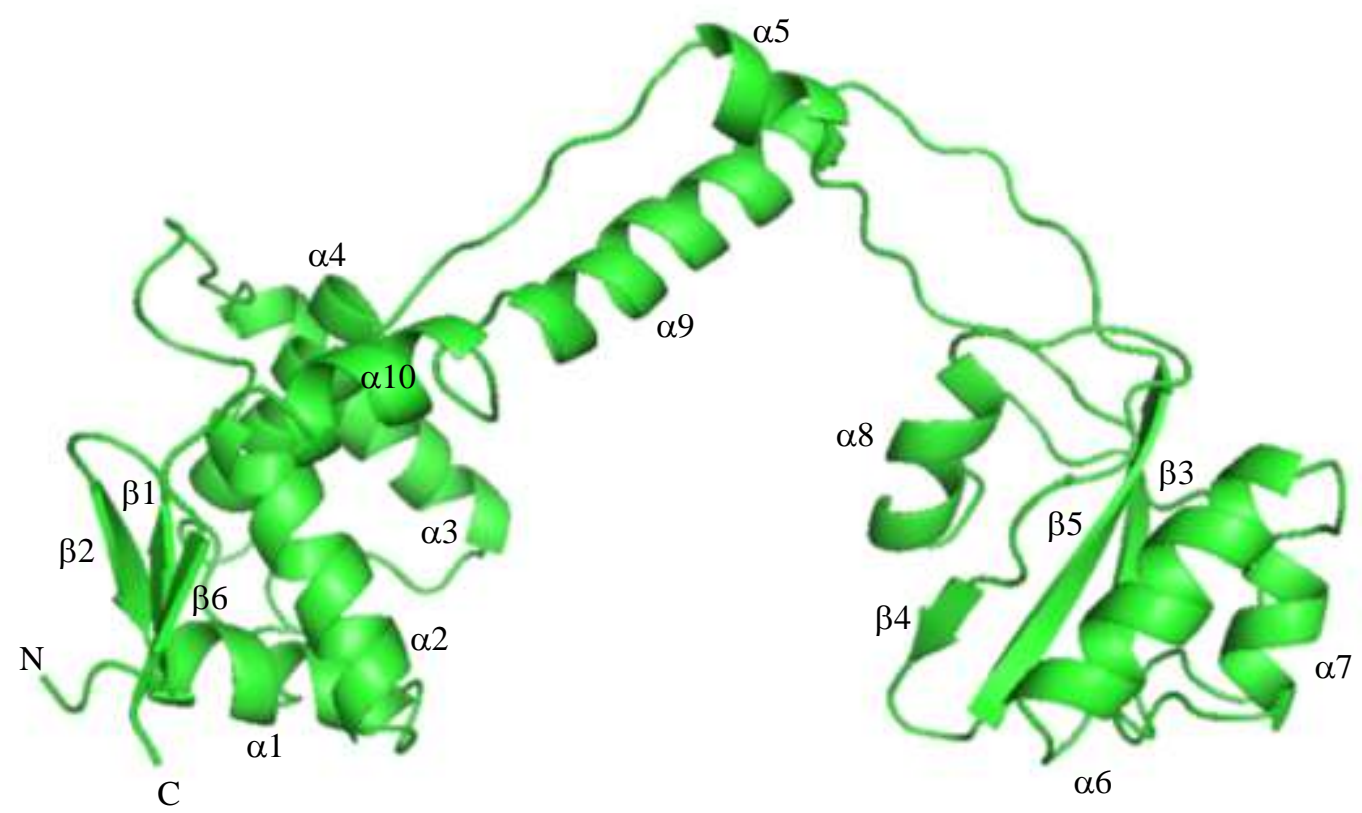

(a)

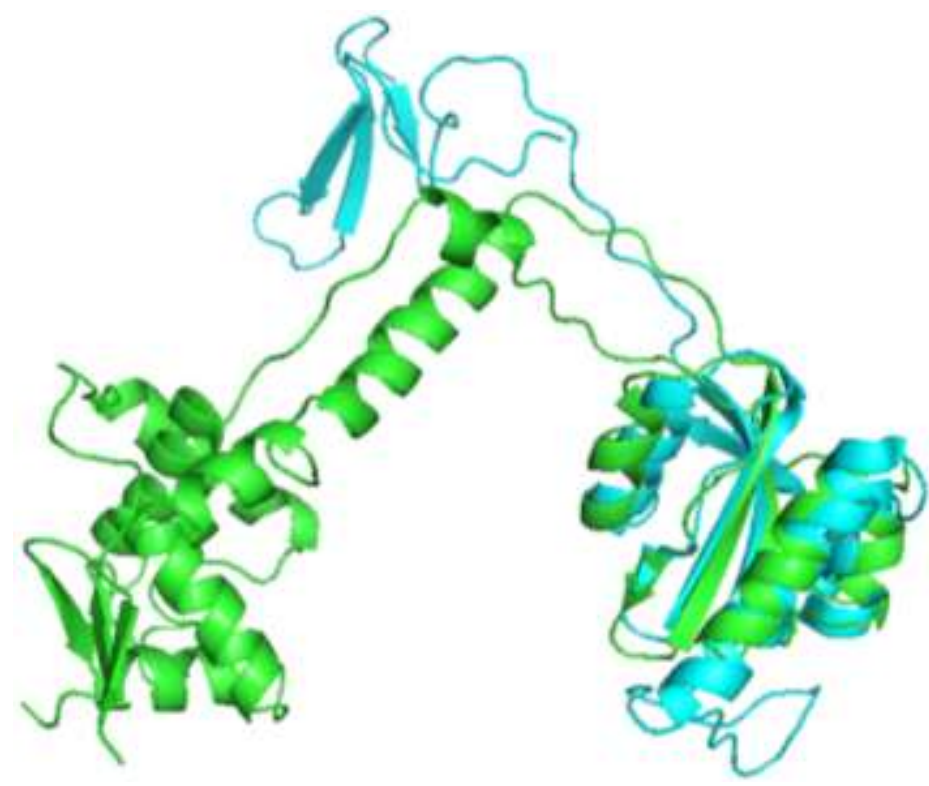

(b)

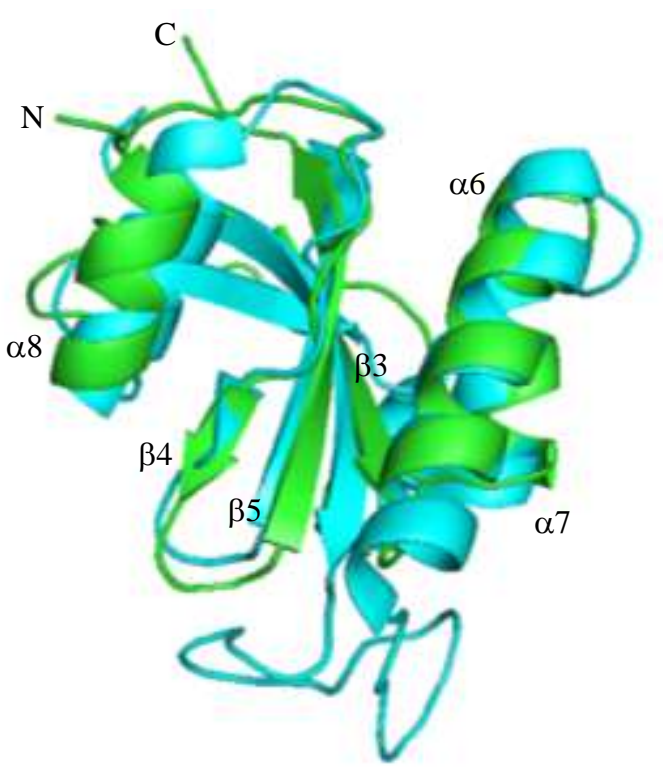

(c) 


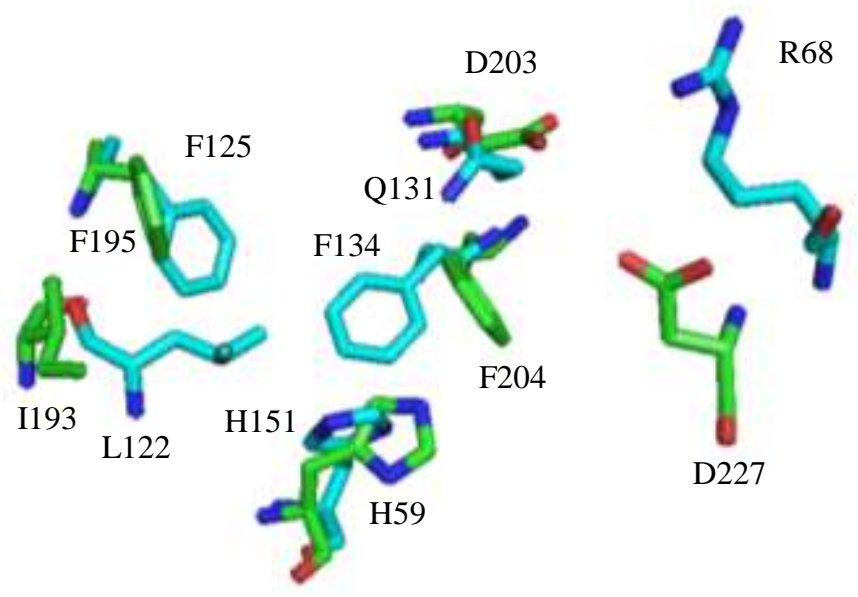

(d)
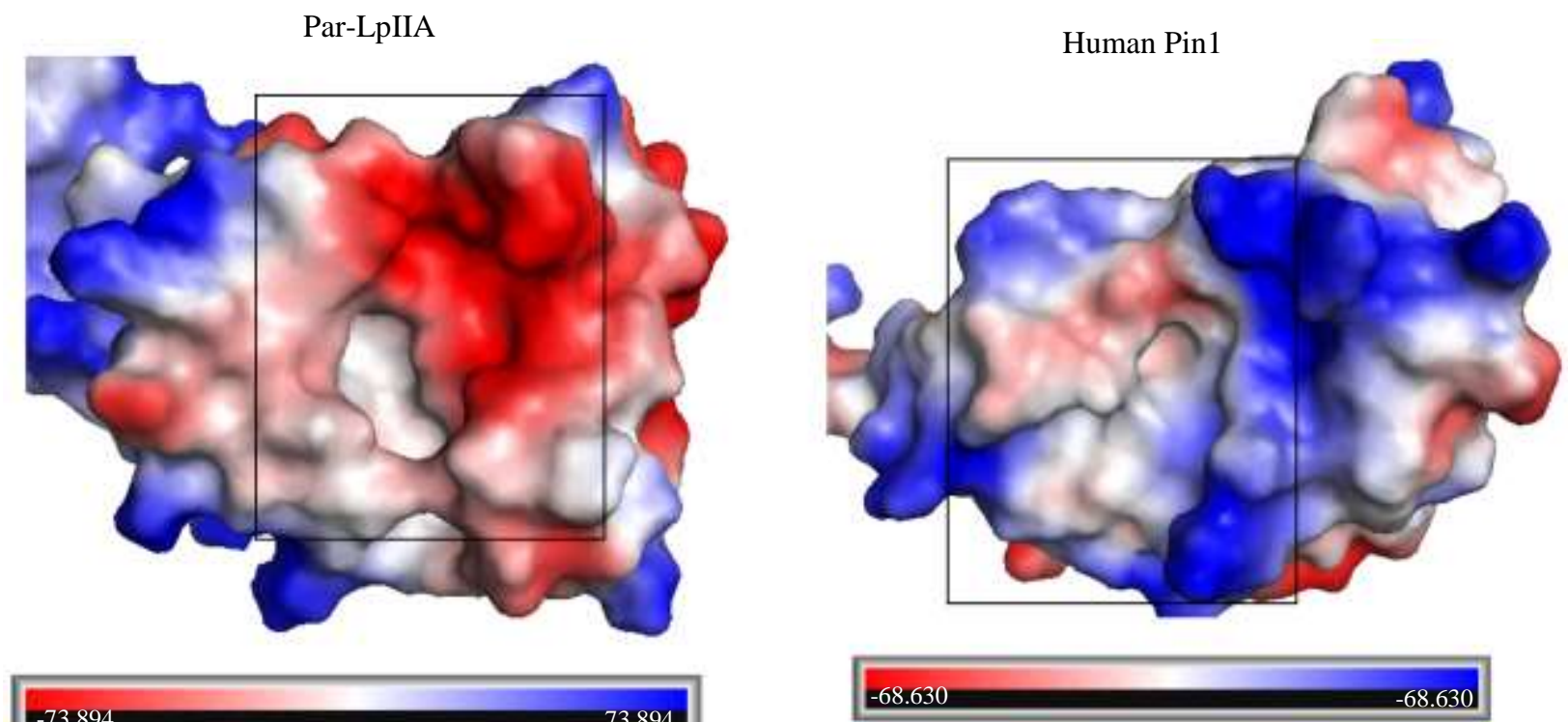

(e)

Fig. 7: (a) The best three-dimensional model Par-LpIIA obtained from structural homology modeling, (b) Structural alignment of the full-length structures of Par-LpIIA (green) with human Pin1 (cyan), (c) Structural alignment of PPIase domain of Par-LpIIA (green) with human Pin1 (cyan), (d) Manual structural alignment of active site residues of human Pin1 (cyan) and Par-LpIIA (green), (e) The surface charges of PPIase domain of Par-LpIIA and human Pin1 as rendered by PyMol's Vacuum Electrostatics. The region where the active sites are located indicated by the box. Red, white and blue stand for negative, neutral and positive surface charges, respectively

More interestingly, structural alignment of PPIase domains of human Pin 1 and Par-LpIIA (Fig. 7d) active site residues of Par-LpIIA were less conserved. Six putative active sites of Par-LpIIA were identified, including His151, Ile193, Phe195, Asp203 and Phe204 and Asp227. His151, Phe195 and Phe204 were well conserved with His59, Phe125 and Phe134 of human Pin1, respectively. Meanwhile Ile193, Asp203 and Asp227 corresponded to Leu122, Gln131 and Arg68, respectively. Also, surface charge around active sites of
Par-LpIIA and human Pin1 are considerably different. The binding pocket of Par-LpIIA is more negatively charged than human Pin1 (Fig. 7e).

\section{Discussion}

LAB is considerably a group of extreme bacteria due to their survival capability at a very low pH (Mbye et al., 2020). It is widely known that extreme organisms' adaptability to certain physiological and or environmental 
stress implied that those organisms are equipped with supporting cellular machinery, including proteins or enzymes (Giordano, 2020). As an example, LAB is known to have a very efficient proton pump allowing the bacteria to maintain their intracellular $\mathrm{pH}$ under very low environmental $\mathrm{pH}$ (Wang et al., 2018). Accordingly, the existence of PPIase family members in this group of bacteria might also imply that protein folding machinery might be influenced by very low environmental $\mathrm{pH}$. Alternatively, this might imply that Par-LpIIA might be functionally required to accelerate the slow isomerization of cis-proline containing proteins upon folding after newly synthesized from the ribosome. It was reported previously that $\mathrm{pH}$ indeed has an effect on the folding rate of proteins (O'Brien et al., 2012; Nemtseva et al., 2019). Rami and Udgaonkar (2001) indicated that the folding rate of protein decreased under extreme alkaline or acidic environment. This implied that at very low environmental $\mathrm{pH}$, the folding rate of proteins inside LAB cells is considerably slow and thus required a catalyst for accelerating the rate. In this respect, Par-LpIIA plays important roles, particularly for cis-proline containing proteins. This is therefore understandable for L. plantarum IIA to have the gene encoding Par-LpIIA

Norgren (2013) highlighted that incorrect gene annotation in whole-genome sequencing may occur due to low-quality genome assembly processes. As a result, some genes that were found in annotation are not existed in genomic DNA, vice versa. Figure 1 confirmed that the gene of Par-LpIIA exists inside the genomic DNA of this strain. Further, Par-LpIIA expressed by L. plantarum IIA is confirmed to be in an active form and thus can accelerate slow cis-proline containing substrate. The PPIase activity against peptide substrate and catalysis against RNase $\mathrm{T}_{1}$ observed in the cell lysate (cytoplasm) of L. plantarum IIA is indeed originated from parvulin-like protein. Alternatively, a parvuline-like protein exists in the cell lysate of $L$. plantarum IIA as a translation product of Par-LpIIA gene. In addition, this is so far the only parvulin reported from LAB family members.

To note, the result also indicated that the cell lysate containing Par-LpIIA exhibited PPIase activity towards phosphorylated and non-phosphorylated substrates. Fanghänel and Fischer (2004) reported that not all parvulin members were able to catalyze the phosphorylated peptide substrate. For example, human Pin1, was able to exhibit PPIase activity towards phosphorylated peptide substrate, but not for human Par14 and Ec-Par (Uchida et al., 1999; Matena et al., 2018; Saeed et al., 2019). The temperature dependency of PPIase activity of CL-LpIIA is understandable as $L$. plantarum IIA is known to be a mesophilic bacterium (Arief et al., 2015). Similarly, a PPIase member from a mesophilic bacterium $E$. coli also increased in the range of $10-25^{\circ} \mathrm{C}$ (Suzuki et al., 2004). Budiman et al. (2011) implied that the nature of the organism dictated the temperature dependency of their PPIase activity. A PPIase member of a psychrophilic bacterium Shewanella sp. SIB1 had shown to be optimum at $10^{\circ} \mathrm{C}$ and remarkably lower at higher temperatures (Suzuki et al., 2004).

Interestingly, the measurement of the PPIase activity of CL-LpIIA indicated that the activity is dependent on $\mathrm{pH}$, with an optimum $\mathrm{pH}$ of 5 . This is in good agreement with the previous evidence showing that the isomerization rate of Ser/Thro-Pro segment is highly affected by the environmental $\mathrm{pH}$ changes (Schutkowski et al., 1998). In general, the most effective catalysis of parvulin was observed at $\mathrm{pH}$ values where the phosphorylated side chain is in its anionic form. Noteworthy, the acidic $\mathrm{pH}$ optimum of LpIIA was found to be slightly lower than the other reported Par (Fanghänel and Fischer, 2004), which might be due to the nature of $L$. plantarum IIA as a bacterium lives in an acidic environment (Arief et al., 2015).

The structural organization of Par-LpIIA, which was organized into two separate domains, apparently followed a common structural feature of parvulin. Yeast parvulin Ess1 and human Pin1 were also organized into two domains, an N-terminal WW domain and a C-terminal PPIase domain and both being important for the in vivo function of these proteins (Kouri et al., 2009; Hanes, 2014). While the PPIase domain is responsible for catalytic activity, the WW domain is known to be important for facilitating a protein-protein interactive event and no involvement in the catalysis (non-catalytic domain) (Maruyama et al., 2004; Sudol, 1996). As BLAST analysis indicated that His 150 to Lys232 which was predicted as PPIase domain, suggested that C-domain of Par-LpIIA is predicted to be a PPIase domain. Meanwhile, the $\mathrm{N}$-domain is predicted to be a homolog of WW-domain. Interestingly, the folding motif analysis using the FastSCOP (http://fastSCOP.life.nctu.edu.tw.) on the homolog WW-domain did not hint any structural motif in the database, which implied that this domain folded into a unique structure.

The presence of a homolog of WW-domain in ParLpIIA might suggest that this protein might interact with the other proteins in its cellular function. The two domains of Par-LpIIA are expected to be cooperatively functional, whereby a homolog of the WW domain is an anchor region for protein substrates for the catalysis by the PPIase domain. Budiman et al. (2011) reported that removing the non-catalytic domain in PPIase abolished the activity against protein substrate due to the lack of an anchoring region. The remarkable acceleration by the cell lysate containing Par-LpIIA might serve as evidence of the cooperativity between these two domains towards the protein substrate. A homolog of the WW domain of 
Par-LpIIA might serve as the binding site for the RNase $\mathrm{T}_{1}$, while the PPIase domain bind to the prolyl bond and catalyze its slow isomerization. This is in good agreement with a proposal of (Budiman et al., 2009), in which the non-PPIase domain is important to facilitate an efficient binding to a protein substrate and therefore maximize the ability of PPIase to catalysis the cis-trans isomerization. To note, some reports also highlighted the ability of parvulin in accelerating the refolding rate of RNase $\mathrm{T}_{1}$ (Kale et al., 2011; Scholz et al., 1997; Uchida et al., 1999; Geitner et al., 2013; Behrens et al., 2001; Vitikainen et al., 2004). Nevertheless, (Scholz et al., 1997) highlighted that the affinity of parvulin towards RNase $T_{1}$ is generally weak and therefore, the catalytic efficiency towards this substrate is 100-fold lower, or more, than that of against a peptide substrate. This explains the finding in this study, whereby the $k_{\text {cat }} / \mathrm{K}_{\mathrm{M}}$ of CL-LpIIA was extremely lower than that of a WFY(pS)PR-pNA substrate. In addition, the ability of Par-LpIIA to catalyze the phosphorylated peptide substrate (WFY(pS)PR-pNA) might be also due to the presence of a homolog of the WW domain. Fanghänel and Fischer (2004) reported that the WW-domain of human Pin1 was found to interact with phosphoserine $(\mathrm{pS})$ or phosphothreonine (pT) containing peptides or proteins.

Less conservation of active site residues of Par-LpIIA might indicate that this protein might employ a unique catalysis mechanism as compared to human Pin1. Interestingly, His59 is well conserved with His151 of Par-LpIIA. Conservation of His59 was reported in most Par family members, suggesting that this protein employs a covalent catalysis mechanism (Fanghänel and Fischer, 2004; Czajlik et al., 2017; Dunyak and Gestwicki, 2017). In human Pin1, the covalent mechanism was explained by the ability of deprotonated His50 to abstract a protein of its adjacent residue (Cys113) to promote a nucleophilic attack to the carbonyl carbon of the prolyl bond. The involvement of Cys residue is known to be a common feature in the catalysis mechanism employed by parvulin (Fanghänel and Fischer, 2004; Dunyak and Gestwicki, 2017).

Interestingly, Cys113 of human Pin1 was not conserved in Par-LpIIA. Besides, no Cys residues were found in the proximity of His 151 of Par-LpIIA. Nevertheless, Ser181 is in close distance to His151, which suggested that Par-LpIIA utilizes the nucleophile of Ser181 to attack the carbonyl carbon of the prolyl bond. Similarly, Ser71 of Par of Arabidopsis thaliana (At-Pin1) also reported being involved in the catalysis, instead of Cys residue (Fanghänel and Fischer, 2004; Lakhanpal et al., 2021). In addition, Cys131 of human Pin1 is also exchanged to Asp74 in human Par14 (Sekerina et al., 2000; Matena et al., 2018; Thapar, 2015), which suggested that the role of Cys in the catalysis is indeed replaceable. The differences in other active site residues and surface charges might also imply the uniqueness of the catalysis mechanism of Par-LpIIA, which might be related to adaptation to the extreme $\mathrm{pH}$ environment of Lp IIA as LAB member. Yet, this assumption remains to be experimentally confirmed. Nevertheless, it is interesting also that the substrate specificity of the CL-LpIIA showed slightly different from that of human Pin1, Eco-Par and human Par14. These differences might be raised due to the unique structural features of Par-LpIIA, particularly in its active sites.

Accordingly, we believe that Par-LpIIA in the cytoplasm is required by L. plantarum IIA to support the protein folding events, particularly for the cis-proly bond containing proteins. This is good agreement with (Trémillon et al., 2012) who proposed PPIase of $L$. lactis as a protein folding helper. A specific feature of Par-LpIIA towards phosphorylated substrate might also imply that this protein is involved in phosphate-mediated cell signaling pathway, including Mitogen-Activated Protein Kinase (MAPK) signaling pathway. Kobatake et al. (2017) reported that MAPK is required by $\mathrm{LAB}$ to overcome oxidative stress. The cellular function of Par-LpIIA, nevertheless, remain to be experimentally confirmed.

\section{Conclusion}

This study clearly confirmed that $L$. plantarum IIA1A5 expresses Par-LpIIA, a member PPIase family protein under parvulin group. The protein was apparently expressed in the cytoplasm of the cell and generate the ability of $L$. plantarum IIA to exhibit specific PPIase activity towards phosphorylated prolyl bond substrate and was able to catalyze the refolding of a cis prolyl bond containing protein (RNase $\mathrm{T}_{1}$ ). Further, the structural homology modeling of Par-LpIIA showed the uniqueness of active site configuration at Par-LpIIA might account for the adaptation mechanism of this protein at a low $\mathrm{pH}$ environment.

\section{Acknowledgement}

Authors thank Muzhen Xu of ETC for technical assistances in this study.

\section{Funding Information}

This study is partly supported by Grant of KRIBB2016 under IPB University (IIA and CB).

\section{Author's Contribution}

Cahyo Budiman: Conceptualization, conducting most of experiments, data analysis and curation, writing the manuscript and funding acquisition. 
Irma Isnafia Arief: Conceptualization, writing manuscript, resources and funding acquisition.

Fernandes Opok: Conducting some experiments, reviewing the manuscript, resources and data analysis.

Muhammad Yusuf: data analysis and writing the manuscript.

All authors read and approved the final manuscript.

\section{Ethics}

This manuscript has not been published elsewhere in part or in entirely. The authors declare that there is no conflict of interest.

\section{References}

Arief, I. I., Jenie, B. S. L., Astawan, M., Fujiyama, K., \& Witarto, A. B. (2015). Identification and probiotic characteristics of lactic acid bacteria isolated from Indonesian local beef. Asian J Animal Sci, 9, 25-36. https://doi.org/10.3923/ajas.2015.25.36

Barik, S. (2006). Immunophilins: for the love of proteins. Cell Mol Life Sci, 63, 2889-2900. https://doi.org/10.1007/s00018-006-6215-3

Bates, P. A., Kelley, L. A., MacCallum, R. M., \& Sternberg, M. J. (2001). Enhancement of protein modeling by human intervention in applying the automatic programs 3D-JIGSAW and 3D-PSSM. Proteins, 5, 39-46. https://doi.org/10.1002/prot.1168

Behrens, S., Maier, R., Cock, H. D., Schmid, F. X., \& Gross, C. A. (2001). The surA periplasmic PPIase lacking its parvulin domains functions in vivo and has chaperone activity. EMBO J, 20(1-2), 285-94. https://doi.org/10.1093/emboj/20.1.285

Bhagavan, N. V., \& Ha, C. E. (2015). Essentials of medical biochemistry: with clinical cases. 2 nd ed. USA: Academic Press.

Bolotin, A., Wincker, P., Mauger, S., Jaillon, O., Malarme, K., Weissenbach, J., ... \& Sorokin, A. (2001). The complete genome sequence of the lactic acid bacterium Lactococcus lactis ssp. lactis IL1403. Genome Research, 11(5), 731-753. https://doi.org/10.1101/gr.GR-1697R

Broadbent, J. R., Cai, H., Larsen, R. L., Hughes, J. E., Welker, D. L., De Carvalho, V. G., ... \& Steele, J. L. (2011). Genetic diversity in proteolytic enzymes and amino acid metabolism among Lactobacillus helveticus strains. Journal of Dairy Science, 94(9), 4313-4328. https://doi.org/10.3168/jds.2010-4068

Budiman, C., Bando, K., Angkawidjaja, C., Koga, Y., Takano, K. \& Kanaya, S. (2009). Engineering of monomeric FK506-binding protein 22 with peptidyl prolyl cis-trans isomerase: importance of $\mathrm{V}$-shaped dimeric structure for binding to protein substrate. FEBS J, 276, 4091-4101. https://doi.org/10.1111/j.1742-4658.2009.07116.x
Budiman, C., Koga, Y., Takano, K., \& Kanaya, S. (2011). FK506-Binding protein 22 from a psychrophilic bacterium, a cold shock-inducible peptidyl prolyl isomerase with the ability to assist in protein folding. Int $\mathrm{J}$ Mol Sci, 12(8), 5261-84. https://doi.org/10.3390/ijms12085261

Budiman, C., Lindang, H. U., Cheong, B. E., \& Rodrigues, K. F. (2018). Inhibition and substrate specificity properties of FKBP22 from a psychrotrophic bacterium, Shewanella sp. SIB1. The Protein Journal, 37(3), 270-279. https://doi.org/10.1007/s10930-018-9772-z

Chen, J., Edwards, S. A., Gräter, F., \& Baldauf, C. (2012). On the cis to trans isomerization of prolylpeptide bonds under tension. J Phys Chem B, 116(31), 9346-9351. https://doi.org/10.1021/jp3042846

Chen, Y., Wu, Y. R., Yang, H. Y., Li, X. Z., Jie, M. M., Hu, C. J., ... \& Yang, Y. B. (2018). Prolyl isomerase Pin1: a promoter of cancer and a target for therapy. Cell Death \& Disease, 9(9), 1-17. https://doi.org/10.1038/s41419-018-0844-y

Czajlik, A., Kovács, B., Permi, P., \& Gáspári, Z. (2017). Fine-tuning the extent and dynamics of binding cleft opening as a potential general regulatory mechanism in parvulin-type peptidyl prolyl isomerases. Scientific Reports, 7(1), 1-12. https://doi.org/10.1038/srep44504

Drouault, S., Anba, J., Bonneau, S., Bolotin, A., Ehrlich, S. D., \& Renault, P. (2002). The peptidyl-prolyl isomerase motif is lacking in PmpA, the PrsA-like protein involved in the secretion machinery of Lactococcus lactis. Applied and Environmental Microbiology, 68(8), 3932-3942. https://doi.org/10.1128/AEM.68.8.3932-3942.2002

Dunyak, B. M., \& Jason, E. G. (2017). Peptidyl-proline isomerases (PPIases): targets for natural products and natural product-inspired compounds: miniperspective. J Med Chem, 59(21), 9622-9644. https://doi.org/10.1021/acs.jmedchem.6b00411

Fanghänel, J., \& Fischer, G. (2004). Insights into the catalytic mechanism of peptidyl prolyl cis/trans isomerases. Front Biosci, 9, 3453-78. https://doi.org/10.2741/1494

Fischer, G., \& Aumüller, T. (2003). Regulation of peptide bond cis/trans isomerization by enzyme catalysis and its implication in physiological processes. Rev Physiol Biochem Pharmacol, 148, 105-150. https://doi.org/10.1007/s10254-003-0011-3

Geitner, A. J., Varga, E., Wehmer, M., Schmid, F. X. (2013). Generation of a highly active folding enzyme by combining a parvulin-type prolyl isomerase from surA with an unrelated chaperone domain. J Mol Biol, 425, 4089-4098. https://doi.org/10.1016/j.jmb.2013.06.038 
Giordano, D. (2020). Bioactive Molecules from Extreme Environments. Marine Drugs, 18(12), 640. https://doi.org/10.3390/md18120640

Hanes, S. D. (2014). The Ess1 prolyl isomerase: Traffic cop of the RNA polymerase II transcription cycle. Biochim Biophys Acta, 1839(4), 316-333. https://doi.org/10.1016/j.bbagrm.2014.02.001

Janowski, B., Wöllner, S., Schutkowski, M. \& Fischer, G. (1997). A protease-free assay for peptidyl prolyl cis/trans isomerases using standard peptide substrates. Anal Biochem, 252, 299-307. https://doi.org/10.1006/abio.1997.2330

Kale, A., Chatchawal, P., Chatrudee, S., C. Jeremy, C., John, B. R., \& David, J. K. (2011). The virulence factor PEB4 (Cj0596) and the periplasmic protein Cj1289 are two structurally related SurA-like chaperones in the human pathogen Campylobacter jejuni. J Biol Chem, 286(24), 21254-65. https://doi.org/10.1074/jbc.M111.220442

Kelley, L. A., \& Sternberg, M. J. (2009). Protein structure prediction on the Web: a case study using the Phyre server. Nat Protoc, 4(3), 363-71. https://doi.org/10.1038/nprot.2009.2

Kiefhaber, T., Quaas, R., Hahn, U. \& Schmid, F. X. (1990a). Folding of ribonuclease $T_{1}$. 1. Existence of multiple unfolded states created by proline isomerization. Biochemistry, 29, 3051-3061. https://doi.org/10.1021/bi00464a023

Kiefhaber, T., Quaas, R., Hahn, U. \& Schmid. F. X. (1990b). Folding of ribonuclease $\mathrm{T}_{1}$. 2. Kinetic models for the folding and unfolding reactions. Biochemistry, 29, 3061-3070. https://doi.org/10.1021/bi00464a024

Kobatake, E., Nakagawa, H., Seki, T., \& Miyazaki, T. (2017). Protective effects and functional mechanisms of Lactobacillus gasseri SBT2055 against oxidative stress. PLoS One, 12(5), e0177106. https://doi.org/10.1371/journal.pone.0177106

Kofron, J. L., Kuzmic, P., Kishore, V., Colon-Bonilla, E., \& Rich, D. H. (1991). Determination of kinetic constants for peptidyl prolyl cis-trans isomerases by an improved spectrophotometric assay. Biochemistry, 30(25), 6127-6134. https://doi.org/10.1021/bi00239a007

Kouri, E. D., Labrou, N. E., Garbis, S. D., Kalliampakou, K. I., Stedel, C., Dimou, M., Udvardi, M. K., Katinakis, P., \& Flemetakis, E. (2009). Molecular and biochemical characterization of the parvulin-type PPIases in lotus japonicus. Plant Physiology, 150, 1160-1173. https://doi.org/10.1104/pp.108.132415

Lakhanpal, S., Fan, J. S., Luan, S., \& Swaminathan, K. (2021). Structural and functional analyses of the PPIase domain of Arabidopsis thaliana CYP71 reveal its catalytic activity toward histone H3. FEBS Letters, $\quad 595(1)$, $145-154$
Lang, K., Schmid, F. X., \& Fischer, G. (1987). Catalysis of protein folding by prolyl isomerase. Nature, 329(6136), 268-270 https://doi.org/10.1038/329268a0

Lee, Y. M., \& Liou, Y. C. (2018). Gears-In-Motion: The interplay of WW and PPIase domains in Pin1. Front Oncol, $8, \quad 469$. https://doi.org/10.3389/fonc.2018.00469

López-Martínez, C., Flores-Morales, P., Cruz, M., Gonzalez, T., Feliz, M., Diez, A., \& Campanera, J. M. (2016). Proline cis-trans isomerization and its implications for the dimerization of analogues of cyclopeptide stylostatin 1: a combined computational and experimental study. Physical Chemistry Chemical Physics, 18(18), 12755-12767. https://doi.org/10.1039/C5CP05937B

Lovell, S. C., Davis, I. W., Arendall, W. B., de Bakker, P. I. W., Word, J. M., Prisant, M. G., ... \& Richardson, D. C. (2003). Structure validation by Calpha geometry: phi, psi and Cbeta deviation. Proteins 50, 437e450. https://doi.org/10.1002/prot.10286

Lu, K. P. (2003). Prolyl isomerase Pin1 as a molecular target for cancer diagnostics and therapeutics. Cancer Cell, 4, 175-80. https://doi.org/10.1016/S1535-6108(03)00218-6

Lu, K. P., Hanes, S. D., \& Hunter, T. (1996). A human peptidyl-prolyl isomerase essential for regulation of mitosis. $\quad$ Nature, 380, 544-547. https://doi.org/10.1038/380544a0

Maruyama, T., Suzuki, R., \& Furutani, M. (2004). Archaeal peptidyl prolyl cis-trans isomerases (PPIases). Front Biosci, 9, 1680-720. https://doi.org/10.2741/1361

Matena, A., Rehic, E., Hönig, D., Kamba, B., \& Bayer, P. (2018). Structure and function of the human parvulins Pin1 and Par14/17. Biol Chem, 399(2), 101-125. https://doi.org/10.1515/hsz-2017-0137

Mbye, M., Baig, M. A., AbuQamar, S. F., El-Tarabily, K. A., Obaid, R. S., Osaili, T. M., ... \& Ayyash, M. M. (2020). Updates on understanding of probiotic lactic acid bacteria responses to environmental stresses and highlights on proteomic analyses. Comprehensive Reviews in Food Science and Food Safety, 19(3), 1110-1124. https://doi.org/10.1111/1541-4337.12554

Mueller, J. W., \& Bayer, P. (2008). Small family with key contacts: par14 and par17 parvulin proteins, relatives of pin1, now emerge in biomedical research. Perspectives in Medicinal Chemistry, 2, PMC-S496. https://doi.org/10.4137/PMC.S496

Nakatsu, Y., Sakoda, H., \& Kushiyama, A. (2011). Peptidyl-prolyl cis/trans isomerase NIMA-interacting 1 associates with insulin receptor substrate-1 and enhances insulin actions and adipogenesis. J Biol Chem, 286, 20812- 20822. https://doi.org/10.1074/jbc.M110.206904 
Nemtseva, E. V., Gerasimova, M. A., Melnik, T. N., \& Melnik, B. S. (2019). Experimental approach to study the effect of mutations on the protein folding pathway. PloS one, 14(1), e0210361. https://doi.org/10.1371/journal.pone.0210361

Norgren, R. B. (2013). Improving genome assemblies and annotations for nonhuman primates. ILAR J, 54(2), 144-53. https://doi.org/10.1093/ilar/ilt037

O'Brien, E. P., Brooks, B. R., \& Thirumalai, D. (2012). Effects of $\mathrm{pH}$ on proteins: predictions for ensemble and single-molecule pulling experiments. J Am Chem Soc, 134(2), 979-87. https://doi.org/10.1021/ja206557y

Rami, B. R., \& Udgaonkar, J. B. (2001). pH-jumpinduced folding and unfolding studies of barstar: evidence for multiple folding and unfolding pathways. Biochemistry, 40(50), 15267-79. https://doi.org/10.1021/bi011701r

Ramm, K., \& Pluckthun, A. (2000). The periplasmic Escherichia coli peptidylprolyl cis,trans-isomerase FkpA. II. Isomerase-independent chaperone activity in vitro. J Biol Chem, 275, 17106-17113. https://doi.org/10.1074/jbc.M910234199

Rippmann, J. F., Hobbie, S., Daiber, C., Guilliard, B., Bauer, M., Birk, J., ... \& Schnapp, A. (2000). Phosphorylation-dependent proline isomerization catalyzed by Pin1 is essential for tumor cell survival and entry into mitosis. Cell Growth and Differentiation-Publication American Association for Cancer Research, 11(7), 409. https://citeseerx.ist.psu.edu/viewdoc/download?doi= 10.1.1.582.8794\&rep=rep1\&type $=$ pdf

Romano, P. G., Edvardsson, A., Ruban, A. V. andersson, B., Vener, A. V., Gray, J. E., \& Horton, P. (2004). Arabidopsis AtCYP20-2 is a light-regulated cyclophilin-type peptidyl-prolyl cis-trans isomerase associated with the photosynthetic membranes. Plant Physiology, 134(4), 1244-1247. https://doi.org/10.1104/pp.104.041186

Rostam, M. A., Piva, T. J., Rezaei, H. B., Kamato, D., Little, P. J., Zheng, W., \& Osman, N. (2015). Peptidyl-prolyl isomerases: functionality and potential therapeutic targets in cardiovascular disease. Clin Exp Pharmacol Physiol, 42(2), 117-24. https://doi.org/10.1111/1440-1681.12335

Saeed, U., Kim, J., Piracha, Z. Z., Kwon, H., Jung, J., Chwae, Y. J., ... \& Kim, K. (2019). Parvulin 14 and parvulin 17 bind to $\mathrm{HBx}$ and cccDNA and upregulate hepatitis $\mathrm{B}$ virus replication from cccDNA to virion in an HBx-dependent manner. Journal of Virology, 93(6). https://doi.org/10.1128/JVI.01840-18

Scholz, C., Rahfeld, J., Fischer, G., \& Schmid, F. X. (1997). Catalysis of protein folding by parvulin. J Mol Biol, 273, 752-762. https://doi.org/10.1006/jmbi.1997.1301
Schutkowski, M., Bernhardt, A., Zhou, X. Z., Shen, M., Reimer, U., Rahfeld, J. U., ... \& Fischer, G. (1998). Role of phosphorylation in determining the backbone dynamics of the serine/threonine-proline motif and Pin1 substrate recognition. Biochemistry, 37(16), 5566-5575. https://doi.org/10.1021/bi973060z

Schwede, T., Kopp, J., Guex, N., \& Peitsch, M. C. (2003). SWISS-MODEL: An automated protein homology-modeling server. Nucleic Acids Res, 31(13), 3381-5. https://doi.org/10.1093/nar/gkg520

Sekerina, E., Rahfeld, J. U., Muller, J., Fanghanel, J., Rascher, C., Fischer, G., \& Bayer, P. (2000). NMR solution structure of hPar14 reveals similarity to the peptidyl prolyl cis/trans isomerase domain of the miotic regulator hPin1 but indicates a different functionality of the protein. J Mol Biol, 301, 1003-17. https://doi.org/10.1006/jmbi.2000.4013

Shaw, P. E. (2002). Peptidyl-prolyl isomerases: a new twist to transcription. EMBO Rep, 3, 521-6. https://doi.org/10.1093/embo-reports/kvf118

Stifani, S. (2018). The multiple roles of peptidyl prolyl isomerases in brain cancer. Biomolecules, 8(4), 112. https://doi.org/10.3390/biom8040112

Sudol, M. (1996). Structure and function of the WW domain. Prog Biophys Mol Biol, 65, 113-132. https://doi.org/10.1016/S0079-6107(96)00008-9

Suzuki, Y., Haruki, M., Takano, K., Morikawa, M., \& Kanaya, S. (2004). Possible involvement of an FKBP family member protein from a psychrotrophic bacterium Shewanella sp. SIB1 in cold-adaptation. Eur J Biochem, 271, 1372-1381. https://doi.org/10.1111/j.1432-1033.2004.04049.x

Thapar, R. (2015). Roles of prolyl isomerases in RNAmediated gene expression. Biomolecules, 5(2), 974-999. https://doi.org/10.3390/biom5020974

Trémillon, N., Morello, E., Llull, D., Mazmouz, R., Gratadoux, J. J., Guillot, A., ... \& Poquet, I. (2012). PpiA, a surface PPIase of the cyclophilin family in Lactococcus lactis. PLoS One, 7(3), e33516. https://doi.org/10.1371/journal.pone.0033516

Tuccinardi, T., \& Rizzolio, F. (2019). Peptidyl-prolyl isomerases in human pathologies. Frontiers in Pharmacology, 10, 794. https://doi.org/10.3389/fphar.2019.00794

Uchida, T., Fujimori, F., Tradler, T., Fischer, G., \& Rahfeld, J. U. (1999). Identification and characterization of a $14 \mathrm{kDa}$ human protein as a novel parvulin-like peptidyl prolyl cis/trans isomerase. FEBS Letters, 446(2-3), 278-282. https://doi.org/10.1016/S0014-5793(99)00239-2

Uchida, T., Takamiya, M., Takahashi, M., Miyashita, H., Ikeda, H., Terada, T., ... \& Hunter, T. (2003). Pin1 and Par14 peptidyl prolyl isomerase inhibitors block cell proliferation. Chemistry \& Biology, 10(1), 15-24. https://doi.org/10.1016/S1074-5521(02)00310-1 
Vitikainen, M., Lappalainen, I., Seppala, R., Antelmann, H., Boer, H., Taira, S., ... \& Kontinen, V. P. (2004). Structure-function analysis of PrsA reveals roles for the parvulin-like and flanking $\mathrm{N}$-and $\mathrm{C}$-terminal domains in protein folding and secretion in Bacillus subtilis. Journal of Biological Chemistry, 279(18), 19302-19314.

https://doi.org/10.1074/jbc.M400861200

Wang, C., Cui, Y., \& Qu, X. (2018). Mechanisms and improvement of acid resistance in lactic acid bacteria. Arch Microbiol, 200(2), 195-201. https://doi.org/10.1007/s00203-017-1446-2
Wojtkiewicz, P., Biernacka, D., Gorzelak, P., Stupak, A., Klein, G., \& Raina, S. (2020). Multicopy suppressor analysis of strains lacking cytoplasmic peptidyl-prolyl cis/trans isomerases identifies three new PPIase activities in Escherichia coli that includes the DksA transcription factor. International Journal of Molecular Sciences, 21(16), 5843.

https://doi.org/10.3390/ijms21165843 